\title{
Reguladores vegetais no enraizamento de estacas lenhosas da amoreira-preta cv. Xavante
}

\section{Plant regulators for rooting of hardwood cuttings of blackberry plants cv. Xavante}

\author{
Aline José Maia ${ }^{1}$; Renato Vasconcelos Botelho ${ }^{2 *}$
}

\section{Resumo}

Com o objetivo de avaliar o emprego de reguladores vegetais no enraizamento de estacas lenhosas da amora-preta cv. Xavante dois experimentos foram conduzidos em casa-de-vegetação. No primeiro, empregou-se o ácido indol butírico (AIB) nas concentrações de $0,1000,1500,2000,2500,3000 \mathrm{mg} \mathrm{L}^{-1}$. No segundo, o regulador utilizado foi o paclobutrazol (PBZ) nas concentrações de 0, 200, 400, 600, 800, 1000 $\mathrm{mg} \mathrm{L}^{-1}$. Em ambos os experimentos as estacas ficaram imersas por 10 segundos nas respectivas soluções. Posteriormente foram plantados em vasos de plástico rígido contendo areia, sendo mantidas em casade-vegetação sob nebulização intermitente. Após 71 dias do plantio, foram avaliadas as seguintes variáveis: porcentagem de estacas enraizadas, comprimento médio das raízes, número de raízes, massa fresca de raízes, porcentagem de estacas com brotações e número de folhas. O tratamento de estacas lenhosas a $2000 \mathrm{mg} \mathrm{L}^{-1} \mathrm{AIB}$ obteve a maior porcentagem de enraizamento (60\%). No entanto, o tratamento a $1000 \mathrm{mg} \mathrm{L}^{-1}$ AIB já atingiu enraizamento elevado (56\%), com $96 \%$ de estacas brotadas e 17,6 raízes por estaca. As Estacas tratadas com PBZ apresentaram maior presença de calo e não enraizaram não sendo possível recomendar este produto para o enraizamento da amoreira-preta cv. Xavante nas concentrações testadas. Palavras-chaves: Propagação vegetativa, ácido indol butírico, paclobutrazol, Rubus spp, estaquia

\begin{abstract}
Aiming to evaluate the use of plant regulators for rooting of hardwood cuttings of blackberry cv. Xavante, two experiments were carried out in a greenhouse. In the first one the concentrations of indolil butyric acid varied in $0,1000,1500,2000,2500$ and $3000 \mathrm{mg} \mathrm{L}^{-1}$. And in the second one, the plant regulator that was used was paclobutrazol at the concentrations of $0,200,400,600,800$ and $1000 \mathrm{mg} \mathrm{L}^{-1}$. For each experiment the base of the cuttings were dipped in the solutions for ten seconds. After that, the cuttings were planted in rigid plastic vases with sand and kept under intermittent misty system. The following variables were evaluated, 71 days after planting: percentage of rooted cuttings, percentage of callus presence, average length of roots, number of roots, fresh weight of roots, percentage of sprouting. The treatment of hardwood cuttings with $2000 \mathrm{mg} \mathrm{L}^{-1}$ IBA had the greatest percentage of rooting $(60 \%)$. Nevertheless, the treatment with $1000 \mathrm{mg} \mathrm{L}^{-1} \mathrm{IBA}$ attained already high rooting percentage (56\%), with $96 \%$ of sprouted cuttings and 17.6 roots per cutting. Cuttings treated with PBZ presented greater callus presence but they did not root, thus it is not possible to recommend this product for rooting of blackberry plants $\mathrm{cv}$. Xavante among the tested concentrations.

Key words: Vegetative propagation, indol butyric acid, paclobutrazol, Rubus spp, cutting
\end{abstract}

1 Engenheira Agrônoma. Acadêmica $5^{\circ}$ Ano de Agronomia - UNICENTRO.

2 Agr. Dr. Prof. Adjunto. Departamento de Agronomia. Universidade Estadual do Centro-Oeste - UNICENTRO. E-mail: rbotelho@unicentro.br

* Autor para correspondência 
No Brasil a cultura da amoreira-preta tem maior importância nos Estados do Rio Grande do Sul, Santa Catarina e Paraná, sendo cultivada também em São Paulo e Minas Gerais (ANTUNES, 2002). A cultura da amoreira-preta se apresenta como uma opção viável para a agricultura familiar (ANTUNES, 2004), devido ao baixo custo de implantação e manutenção do pomar, pouca utilização de defensivos agrícolas e retorno rápido de capital, pois já no segundo ano entra em produção, podendo ainda ser utilizada para consumo in natura e na fabricação de geléias e polpa (FACHINELLO; HOFFMANN; SANTOS, 1994).

A cultivar Xavante é a primeira cultivar brasileira de amoreira-preta de porte ereto, hastes vigorosas e sem espinhos, tendo sido lançada pela Embrapa Clima Temperado em conjunto com a Universidade de Arkansas, Estados Unidos. É uma cultivar de baixa necessidade de frio e de boa produção (ANTUNES, 2004).

A propagação da amoreira-preta pode ser realizada por estacas de raízes, por ocasião do repouso vegetativo, além de brotos (rebentos) originados das plantas cultivadas (CALDWELL; MOORE, 1982). O uso de estacas herbáceas e lenhosas também é uma alternativa viável, podendo ser aproveitadas (RASEIRA; SANTOS; RASEIRA, 1992).

Segundo Peruzzo, Dalbó e Piccoli (1995), a multiplicação rápida de mudas de amoreira-preta pode ser conseguida pelo enraizamento de estacas herbáceas com quatro a cinco gemas sob nebulização, sendo que a produção de mudas por este método pode ser conseguida durante todo o período de crescimento da planta matriz.

A utilização de estacas lenhosas na propagação da amora-preta é uma prática que tem sido utilizada, visto que, durante o período de dormência, por ocasião da poda, obtém-se grande quantidade de ramos que podem ser utilizados para a confecção de estacas. A estaquia de ramos lenhosos, retirados por ocasião da poda de inverno, pode maximizar a utilização do material vegetal e não apenas eliminá-lo como subproduto (ANTUNES; CHALFUN; REGINA, 2000).
Antunes, Chalfun e Regina (2000), trabalhando com estacas lenhosas de amoreira-preta, observaram que a cultivar Caingangue apresentou maior vigor que as demais cultivares testadas, refletindo em maior matéria seca de parte aérea $(2.060 \mathrm{mg})$ e raiz (660mg). Os maiores porcentuais de enraizamento e brotação foram, respectivamente, das cultivares Brazos $(97,9 ; 97,9)$, Guarani $(95,8 ; 93,7)$, Tupy $(93,7$; $97,4)$, Caingangue $(93,7 ; 95,8)$ e Ébano $(89,5 ; 93,7)$. As cultivares Comanche e Cherokee e Seleção 97 apresentaram resultados inferiores a 50\% em todas as características avaliadas.

Segundo Zuffellato-Ribas e Rodrigues (2001), o enraizamento de estacas é influenciado pela auxina, embora esta não seja, a única substância envolvida. $\mathrm{Na}$ estaquia, a auxina natural produzida nas folhas e nas gemas, move-se naturalmente para a parte inferior da planta, aumentando a sua concentração na base do corte, junto com os açúcares e outras substâncias nutritivas. A formação de raízes é aparentemente dependente de um nível ótimo de auxina, em relação a estas substâncias. Em numerosas plantas, o enraizamento é grandemente aumentado pela adição de auxinas sintéticas.

De acordo com Pires e Biasi (2003), o ácido indol butírico (AIB) é provavelmente o melhor regulador vegetal de uso geral, porque não é tóxico para a maioria das plantas, mesmo em altas concentrações, é bastante efetivo para um grande número de espécies e relativamente estável, sendo pouco suscetível à ação dos sistemas de enzimas de degradação de auxinas. Tratamentos com o ácido indoli butírico promovem o aumento da porcentagem de enraizamento de estacas, aceleram a iniciação radicular, aumentam o número e qualidade de raízes produzidas e aumentam a uniformidade do enraizamento (FACHINELLO et al., 1995)

O paclobutrazol (PBZ) ou -[4(clorofenil) metil1H-1,2,4,- triazol-1-etanol], é um inibidor da biossíntese de giberelinas, que em baixas concentrações tem estimulado a formação de raízes em diversas espécies. Geneve (1990) observou a 
promoção de raízes em estacas de pecíolos juvenis de hera (Hedera helix L.) pela aplicação de paclobutrazol. A promoção de raízes adventícias pelo paclobutrazol tem sido atribuída à sua atividade em inibir a síntese de giberilina, ou a seu efeito de retardar o crescimento, o qual pode aumentar o transporte de assimilados e/ou hormônios das plantas, para a base das estacas.

Estacas lenhosas de algumas cultivares de amoreira-preta são difíceis de enraizar, por apresentarem um maior grau de lignificação e baixos níveis de auxina endógena. Dentro deste contexto, o presente trabalho tem como objetivo avaliar o enraizamento de estacas lenhosas de amoreira-preta cv. Xavante com diferentes concentrações dos reguladores vegetais AIB e PBZ.

O material propagativo da amoreira-preta cv. Xavante utilizado para os experimentos foi retirado do pomar experimental do Departamento de Agronomia da Universidade Estadual do CentroOeste (UNICENTRO), em Guarapuava-PR, em 03.08.2005, por ocasião da poda de inverno em plantas em segundo ano após plantio.

As estacas lenhosas foram preparadas com três a quatro gemas cada, cerca de $20 \mathrm{~cm}$ de comprimento, cortando-se a porção inferior em bizel, em posição oposta a gema; e na porção superior reta, acima de uma gema. Em seguida as estacas foram tratadas na sua parte basal com os reguladores vegetais, por 10 segundos.

Foram realizados dois experimentos: um com AIB nas concentrações de $0,1000,1500,2000,2500$ e $3000 \mathrm{mg} \mathrm{L}^{-1}$, e o outro com PBZ nas concentrações de $0,200,400,600,800,1000 \mathrm{mg} \mathrm{L}^{-1}$
Depois do tratamento com reguladores vegetais, as estacas foram plantadas em vasos de plástico rígido, medindo $45 \times 17 \mathrm{~cm}$ e $14 \mathrm{~cm}$ de altura, tendo como substrato areia e mantidas em casa-devegetação sob nebulização intermitente, por 15 segundos a cada 10 minutos, das 8:00 h às 18:00 h. No dia 03 de agosto de 2005, foram plantadas as estacas lenhosas, sendo submetidas à avaliação no dia 14 de outubro de 2005. O delineamento experimental adotado foi inteiramente casualizado, com seis repetições e cada parcela experimental constituída por um vaso contendo cinco estacas cada.

Após 71 dias, as seguintes variáveis foram avaliadas: porcentagem de estacas enraizadas, porcentagem de estacas com calo, comprimento médio das raízes, número de raízes, massa fresca de raízes, porcentagem de estacas com brotações. Os resultados obtidos foram submetidos à análise de variância e quando significativo realizou-se a análise de regressão polinomial.

A aplicação de AIB apresentou efeito quadrático de concentrações para a variável porcentagem de enraizamento. A concentração estimada para a maior porcentagem de enraizamento foi de $1826 \mathrm{mg} \mathrm{L}^{-1} \mathrm{de}$ AIB, correspondendo a $59,7 \%$ de enraizamento (Figura 1). No entanto, na concentração de 1.000 $\mathrm{mg} \mathrm{L} \mathrm{L}^{-1}$, a porcentagem de enraizamento já foi relativamente elevada alcançando 56\%, muito próximo ao ponto máximo estimado. Para as variáveis comprimento médio de raízes, número de raízes, porcentagem de brotação e porcentagem de estacas com calo não houve feito significativo de concentrações de AIB (Tabela 1). 
Tabela 1. Comprimento médio de raízes, número de raízes por estaca, massa fresca de raízes, porcentagem de estacas com brotações e porcentagem de estacas com calo de estacas lenhosas da amoreira-preta cv. Xavante tratadas com diferentes concentrações de AIB (Guarapuava-PR, 2005).

\begin{tabular}{|c|c|c|c|c|c|}
\hline Tratamentos & $\begin{array}{l}\text { Comprimento } \\
\text { raízes }(\mathrm{cm})\end{array}$ & $\begin{array}{l}\mathrm{N}^{\mathrm{o}} \text { raízes por } \\
\text { estaca }\end{array}$ & $\begin{array}{l}\text { Massa fresca } \\
\text { raízes }(\mathrm{g})\end{array}$ & Brotações (\%) & $\begin{array}{c}\text { Estacas com calo } \\
(\%)\end{array}$ \\
\hline AIB $0 \mathrm{mg} \mathrm{L}^{-1}$ & - & - & 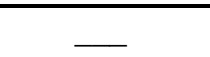 & 100 & 40 \\
\hline AIB $1000 \mathrm{mg} \mathrm{L}^{-1}$ & 5,4 & 17,6 & 1,8 & 96 & 52 \\
\hline AIB $1500 \mathrm{mg} \mathrm{L}^{-1}$ & 5,4 & 18,5 & 1.6 & 94 & 52 \\
\hline AIB $2000 \mathrm{mg} \cdot \mathrm{L}^{1}$ & 6,3 & 22,9 & 1,7 & 96 & 68 \\
\hline AIB $2500 \mathrm{mg} \cdot \mathrm{L}^{1}$ & 3,2 & 14,7 & 0,6 & 88 & 60 \\
\hline AIB $3000 \mathrm{mg} \cdot \mathrm{L}^{1}$ & 6,8 & 18,9 & 2,2 & 92 & 44 \\
\hline C.V. $(\%)$ & 34,4 & 36,7 & 64,1 & 11,6 & 65,2 \\
\hline Valor F & $3,5802^{\mathrm{ns}}$ & $1,2624^{\mathrm{ns}}$ & $2,4264^{\mathrm{ns}}$ & $0,8667^{\mathrm{ns}}$ & $0,5541^{\mathrm{ns}}$ \\
\hline
\end{tabular}

n.s. = não significativo.

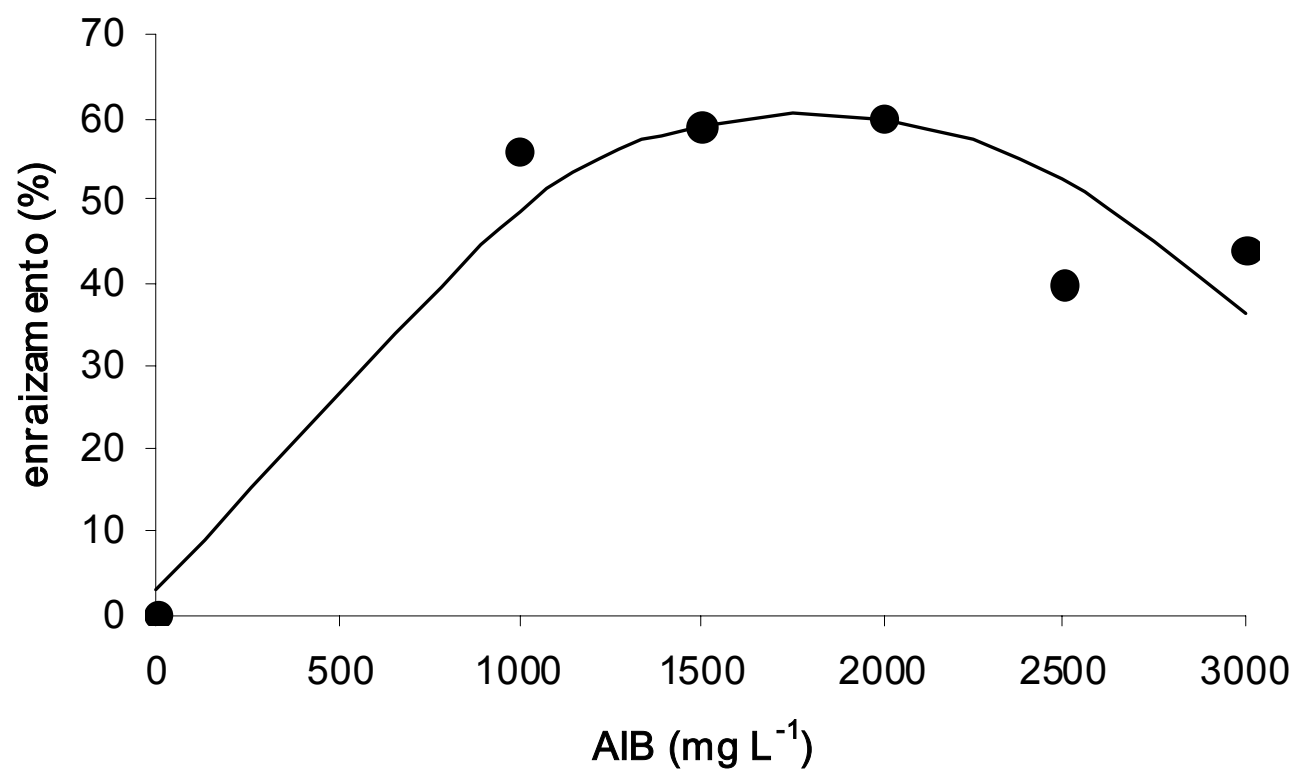

Figura 1. Porcentagem de estacas lenhosas enraizadas $\left(y=2,9893+0,0628 x-0,000017 x^{2}, r^{2}=87,9 \% * *\right)$ da amoreirapreta cv. Xavante tratadas com diferentes concentrações de AIB (Guarapuava-PR, 2005).

Para as estacas tratadas com PBZ, não houve efeito significativo para a variáveis porcentagem de enraizamento e porcentagem de brotação (Tabela 2). O enraizamento variou de 0 a $12 \%$ e a brotação de 62 a 100\%. Em relação à porcentagem de estacas com calo, houve efeito quadrático de doses de PBZ, tendo sido estimada a dose de $578,96 \mathrm{mg}$. $\mathrm{L}^{-1}$ de PBZ para a maior porcentagem de calo $(53,78 \%)$ ocorrendo decréscimo nas doses maiores (Figura 2). Para as demais variáveis, não foi possível estimar as médias devido às baixa porcentagens de enraizamento. 
Tabela 2. Porcentagem de estacas enraizadas e porcentagem de estacas com brotações da amoreira-preta cv. Xavante tratadas com diferentes concentrações de PBZ (Guarapuava-PR, 2005).

\begin{tabular}{|c|c|c|}
\hline Trotomento & Enraizamento estacas (\%) & Brotações (\%) \\
\hline PBZ $0 \mathrm{mg} \mathrm{I}^{-1}$ & 12 & 100 \\
\hline PBZ $200 \mathrm{mg} \mathrm{L}^{-1}$ & 8 & 100 \\
\hline PBZ $400 \mathrm{mg} \mathrm{L}^{-1}$ & 4 & 96 \\
\hline PBZ $600 \mathrm{mg} \mathrm{L}^{-1}$ & 12 & 62 \\
\hline PBZ $800 \mathrm{mg} \mathrm{L}^{-1}$ & 10 & 70 \\
\hline PBZ $1000 \mathrm{mg} \mathrm{L}^{-1}$ & 0 & 100 \\
\hline C.V. (\%) & 180,0 & 6,48 \\
\hline Valor F & $0,8905^{\mathrm{ns}}$ & $09944^{\mathrm{ns}}$ \\
\hline
\end{tabular}

n.s. = não significativo

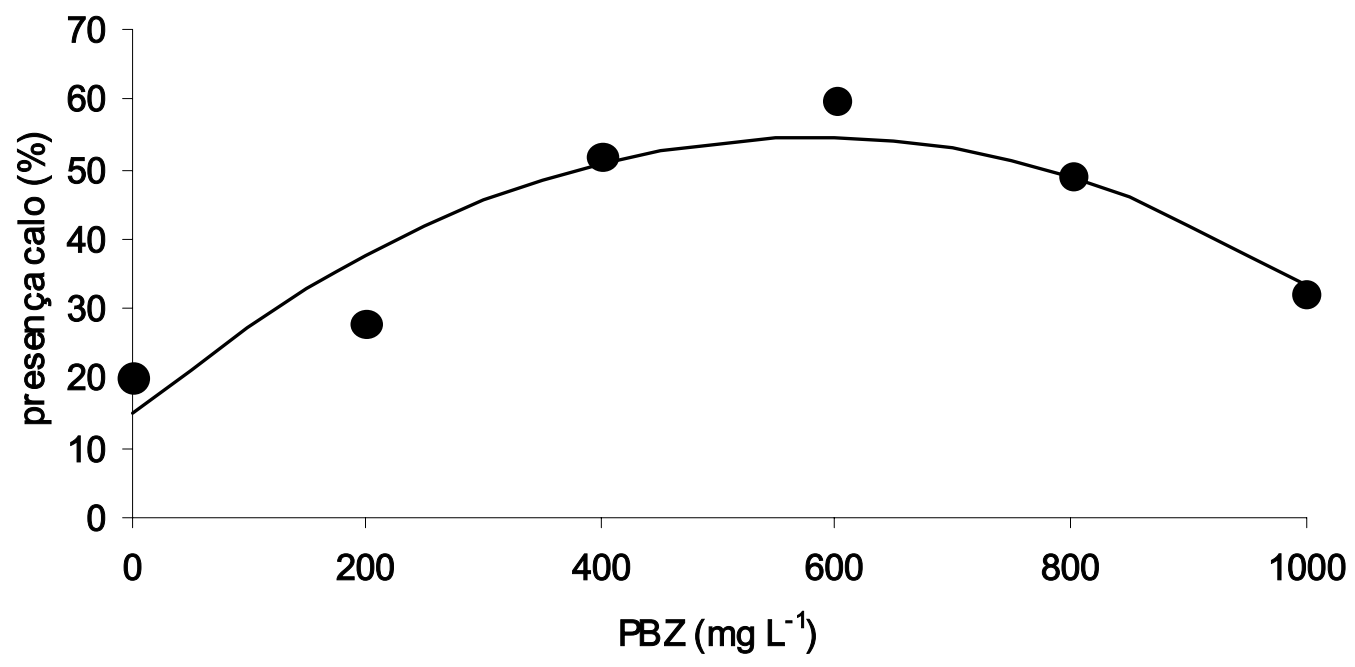

Figura 2. Porcentagem de estacas com calo $\left(y=15,0456+0,1369 x-0,00011 x^{2}, r^{2}=86,7 \% *\right)$ da amoreira-preta cv. Xavante tratadas com diferentes concentrações de PBZ (Guarapuava-PR, 2005).

Estes resultados estão de acordo com Villa et al. (2003), que testaram diferentes concentrações de AIB em estacas lenhosas da amoreira-preta cv. Guarani e obtiveram maiores percentuais de estacas enraizadas e brotadas, número de folhas e de brotos e peso da matéria seca das brotações com aplicação de $2000 \mathrm{mg} \mathrm{L}^{-1}$ de AIB. Segundo Bastos (2002), a utilização de auxina exógena, como é o caso do AIB, pode influenciar no aumento do enraizamento, já que as estacas lenhosas apresentam maior grau de lignificação e baixos níveis de auxina endógena.
De acordo com Ono e Rodrigues (1996), o maior grau de lignificação pode estar correlacionado negativamente com a auxina, e enzimas tais como as peroxidases estão envolvidas tanto na síntese de lignina como na degradação de auxina. Conforme Janick (1996), isso pode ser devido à formação de inibidores que, na maturidade servem de obstáculo à formação de raízes. Deste modo, estaca de difícil enraizamento, torna-se de fácil enraizamento, quando recebem uma lavagem, a fim de remover o inibidor. 
No entanto, esta resposta à aplicação de AIB varia em função da cultivar. Em trabalhos com a amoreira-preta cv. Brazos, tanto Villa et al. (2003), como Augusto, Biasi e Telles (2006) observaram alta porcentagem de enraizamento de estacas, mesmo quando não tratadas com AIB. De forma semelhante, Dantas et al. (2000) encontraram o melhor enraizamento da amoreira-preta cv. Caingangue no meio de cultura sem a auxina ANA (ácido naftalenoacético). Segundo Assis e Teixeira (1998), há várias evidências de que a formação de raízes é geneticamente controlada, pois há bastante variação entre espécies e mesmo entre clones.

O PBZ não interferiu significativamente na porcentagem de enraizamento, porém apresentou maiores percentuais de estacas com calo. Embora, sejam fenômenos independentes, a formação de calo e o aparecimento de raízes adventícias, são influenciados, na maioria dos casos, pelos mesmos fatores e podem ocorrer simultaneamente. No entanto, não há uma relação direta entre a formação de calo e o enraizamento (FACHINELLO et. al., 1995). Nachtigal et al. (1994), observaram reação inversa entre a porcentagem de estacas enraizadas e de calo, em araçazeiro (Psidium cattleyanum Sabine).

O tratamento de estacas lenhosas a $2000 \mathrm{mg} \mathrm{L}^{-1}$ AIB obteve a maior porcentagem de enraizamento (60\%). No entanto, o tratamento a $1000 \mathrm{mg} \mathrm{L}^{-1} \mathrm{AIB}$ já atingiu enraizamento elevado (56\%), com $96 \%$ de estacas brotadas e 17,6 raízes por estaca; justificando novos trabalhos com menores concentrações, visando a redução do custo de tratamento. Estacas tratadas com PBZ apresentaram maior presença de calo e não enraizaram não sendo possível recomendar este produto para o enraizamento da amora-preta cv. Xavante nas doses testadas.

\section{Referências}

ANTUNES, L. E. C. Amora-preta: nova opção de cultivo no Brasil. Ciência Rural, Santa Maria, v. 32, n. 1, p. 151$158,2002$.
ANTUNES, L. E. C.; CHALFUN, N. N. J.; REGINA, M. A. Propagação de cultivares de amoreira-preta (Rubus spp) através de estacas lenhosas. Revista Brasileira de Fruticultura, Jaboticabal, v. 22, n. 2, p. 195-199, 2000.

ANTUNES, L. E. C. Aspectos técnicos da cultura da amora-preta. Pelotas: Embrapa Clima Temperado, 2004.

ASSIS, T. F.; TEIXEIRA, S. L. Enraizamento de plantas lenhosas. In: TORRES, A.; CALDAS, L. S.; BUSO, J. A. Cultura de tecidos e transformação genética de plantas. Brasília: Embrapa-SPI/Embrapa CNPH, 1998. v.1, p. 261296.

AUGUSTO, C. S. S.; BIASI, L. A.; TELLES, C. A. Enraizamento e aclimatização de plantas micropropagadas de amoreira-preta cv. Brazos. Revista Brasileira de Fruticultura, Jaboticabal, v. 28, n. 3, p. 473-476, 2006.

BASTOS, D. C. Efeito da época de coleta, estádio do ramo e do tratamento com IBA no enraizamento de estacas de caramboleira (Averhoa carambola L.). 2002. Dissertação (Mestrado em Agronomia) - Faculdade de Ciência Agrárias e Veterinárias, Universidade Estadual Paulista, Jaboticabal.

CALDWELL, J. D.; MOORE, J. N. Inheritance of fruit size in the cultived tetraploid blackberry [Rubus (Tourn) L. subgenus Eubatus]. Journal of the American Society for Horticultural Science, Alexandria, v. 107, n. 4, p. 628-633. 1982.

DANTAS, A. C. M.; CERETTA, M.; FORTES, G. R. L.; COUTINHO, E. F. Enraizamento in vitro da amoreira-preta (Rubus sp.), cultivar Caingangue. Agropecuária de Clima Temperado, Pelotas, v. 3, n. 2, p. 123-130, 2000.

FACHINELLO, J. C.; HOFFMANN, A.; SANTOS, A. M. Amoreira-preta, framboesa e mirtilo: pequenas frutas para o sul do Brasil. In: CONGRESSO BRASILEIRO DE FRUTICULTURA, 13., 1994, Salvador. Anais... Salvador: SBF, 1994, v.3, p. 989-990.

FACHINELLO, J. C.; HOFFMANN, A.; NACHTIGAL, J. C.; KERSTEN, E.; FORTES, G. R. L. Propagação de plantas frutiferas de clima temperado. 2.ed. Pelotas: UFPel, 1995.

GENEVE, R. L. Root formation on cuttings of Ivy treated with paclobutrazol or uniconazole. HortScience, Alexandria, v. 25, n. 6, p. 709, 1990.

JANICK, J. A ciência da horticultura. Rio de Janeiro: F. Bastos, 1996.

NACHTIGAL, J. C.; HOFFMANN, A.; KLUGUE, R. A.; FACHINELLO, J. C.; MAZZINI, A. R. Enraizamento de estacas semilenhosas de araçazeiro (Psidium cattleyanum Sabine) com o uso do ácido indolilbutírico. Revista Brasileira de Fruticultura, Cruz das Almas, v. 16, n. 1, p 229-235, abr. 1994. 
ONO, E. O.; RODRIGUES, J. D. Aspectos da fisiologia do enraizamento de estacas caulinares. Jaboticabal: FUNEP, 1996.

PERUZZO, E. L.; DALBÓ, M. A. PICCOLI, P. S. Amorapreta: variedade e propagação. Agropecuária Catarinense, Florianópolis, v. 8, n. 3, p. 53-55, 1995.

PIRES, E. J. P.; BIASI, L. A . Propagação da videira. In: POMMER, C. V. Uva: tecnologia de produção, póscolheita, mercado. Porto Alegre: Cinco Continentes, 2003. p. 295-350.
RASEIRA, A.; SANTOS, A. M.; RASEIRA, M. C. B. Caingangue, nova cultivar de amora-preta para consumo “ in natura”. Horti Sul, Pelotas, v. 2, n. 3, p. 11-12, 1992.

VILLA, F.; PIO, R.; CHLFUN, N. N. J.; GONTIJO, T. C. A.; DUTRA, L. F. Propagação de amoreira-preta utilizando estacas lenhosas. Ciência e Agrotecnologia, Lavras, v. 27, n. 4, p. 829-834, 2003.

ZUFFELLATO-RIBAS, K. C.; RODRIGUES, J. D. Estaquia: uma abordagem dos principais aspectos fisiologicos. Curitiba: UFPR, 2001. 
